\title{
A performatividade das figuras na dança coral de Lia Rodrigues em Piracema
}

The performativity of the figures

in Lia Rodrigues' coral dance in Piracema

\section{Gabriela Machado Freire Tournillon Alcofra Julia Ziviani Vitiello}

Gabriela Machado Freire Tournillon Alcofra Mestrado no pelo Programa de Pós-Graduação em Artes da Cena do Instituto de Artes da Universidade Estadual de Campinas (Unicamp). Artista da dança e pesquisadora.

Julia Ziviani Vitiello Professora Titular do Departamento de Artes Corporais da Unicamp.

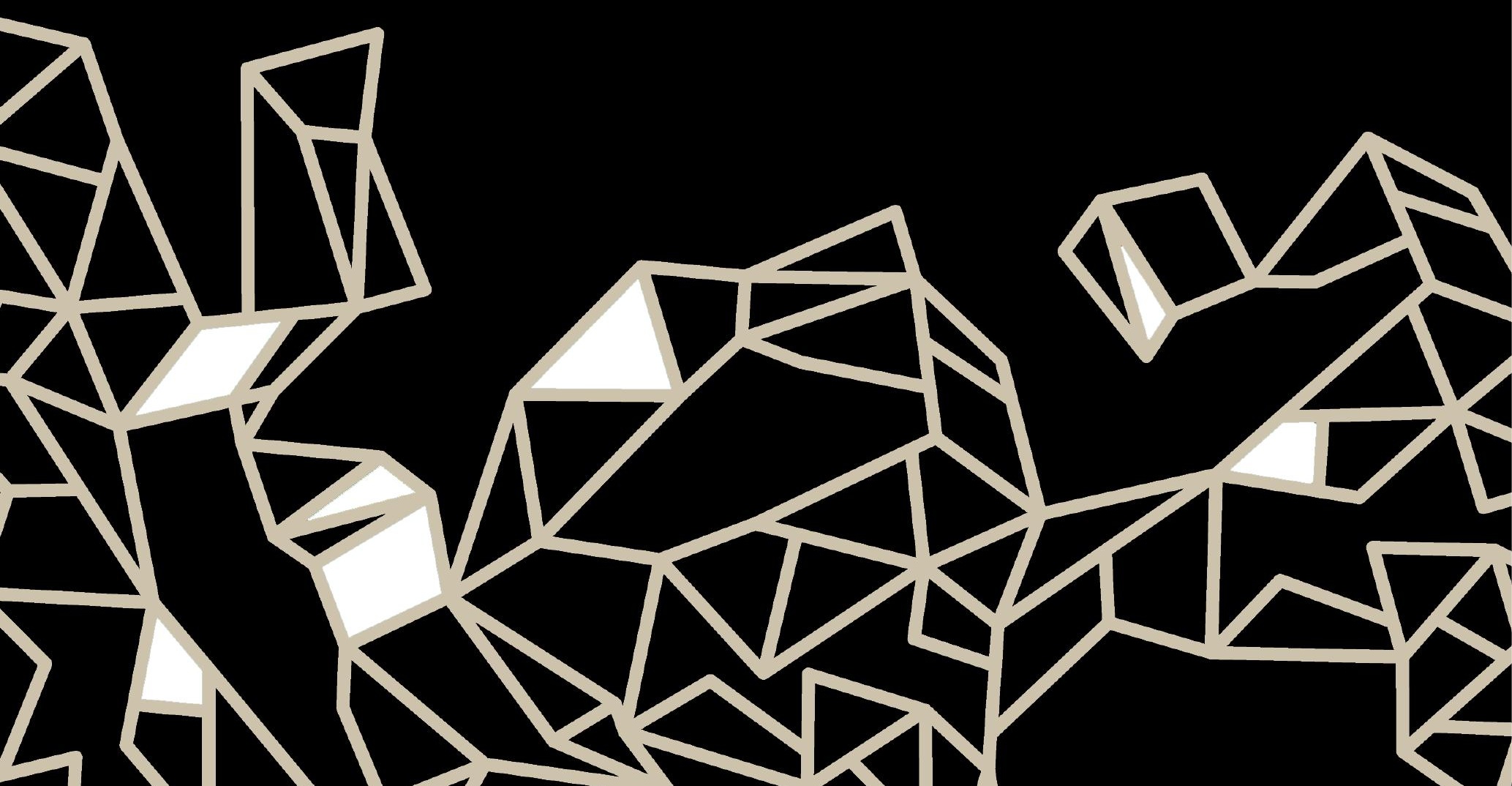




\section{Resumo}

A partir de um breve histórico das transformações no conceito e na prática da dramaturgia tanto no teatro quanto na dança desde a metade do século XX no ocidente, este artigo busca refletir sobre a representação e a apresentação, a performatividade e a representatividade na construção da cena contemporânea, relacionando sujeito e contexto tanto como autor quanto como espectador, tendo como objeto de estudo o espetáculo Piracema, da Lia Rodrigues Companhia de Danças.

Palavras-chave: Dramaturgia, Performatividade, Representatividade.

\section{Abstract.}

From a brief history of the changes in the concept and practice of Western dramaturgy, both in theater and in dance, since the middle of the 20th century, this article aims to contemplate the representation and presentation, performativity and representativeness in the construction of the contemporary scene, relating subject and context both as author and as a spectator, having as object of study Piracema, a Lia Rodrigues Dance Company presentation.

Keywords: Dramaturgy, Performativity, Representativeness.

\section{Introdução}

A cena contemporânea, incluindo o teatro e a dança, se encontra hoje em uma fronteira movediça. Se no início do século $X X$ cada linguagem possuía um espaço categórico bem definido, com materiais e meios próprios e previamente delineados, a partir da metade desse mesmo século os artistas passaram a questionar seus suportes e metodologias, permitindo-se contaminar pela transdisciplinaridade artística, colocando em xeque as categorias estabelecidas. O produto deu lugar ao processo, "em vez da permanência, a transitoriedade; a unicidade se esvai frente à reprodutibilidade; contra a autonomia, a contextualização; a autoria se esfacela frente às poéticas da apropriação; a função intelectual é determinante na recepção" (FREIRE, 2006, p. 9). 
Em movimentos paralelos, tanto a dança como o teatro caminharam em sentidos convergentes. A crise da modernidade e da representação trouxe uma nova forma de o homem estar no mundo e percebê-lo, refletindo em mudanças nas suas produções artísticas. Como lembra Harvey (2006), é justamente na passagem da modernidade para a pós-modernidade que o artista passa a se preocupar mais com a linguagem do que com a representação. A entrada e disseminação de novas mídias, como a fotografia e o cinema, o avanço tecnológico que permitia novas técnicas de manufatura e reprodutibilidade, a aceleração na percepção temporal e o crescente individualismo transformaram a arte, seus modos de execução e apreensão.

Essas mudanças problematizaram os conceitos de dramaturgia e representatividade até então estabelecidos, em que o texto narrativo estava no cerne da condução dramatúrgica. A estética representativa não fazia mais sentido na concorrência com o realismo audiovisual, transformando a dramaturgia em uma polifonia de vozes. A coletividade se dissolve em meio à fragmentação em busca de uma afirmação individual.

É na contemporaneidade, porém, que surge uma nova forma de estar no mundo, retomando o sentimento coletivo, afirmando-se como coralidade. Para Triau (2003), a coralidade está no cerne dessa nova era ao tentar juntar processos e fragmentos de um mundo esfacelado, revelando tanto o desejo de pertencimento como sua fragilidade de ser. Assim, como o sujeito se afirma nesse novo contexto que modifica também sua forma de produzir arte? Ainda é possível falar em linguagens e categorias artísticas?

\section{As possíveis dramaturgias na cena contemporânea}

Para observar as transformações do conceito de dramaturgia, podemos fazer um raso sobrevoo para lembrar as mudanças artísticas que aconteceram a partir da metade do século XX no ocidente. Pelo viés do teatro, podemos ver a desconstrução da hierarquia textual na montagem cênica, fazendo prevalecer a apresentação sobre a representação. $O$ ator se coloca como corpo expressivo diante das máscaras e das personagens.

Por outro lado, a dança, a partir dos anos 1950, se permite experimentações cênicas, quebrando a estrutura narrativa que prevalecia desde a dança clássica e moderna, buscando a especificidade da dança enquanto lingua- 
gem, dando autonomia ao movimento e ao gesto. Questiona-se o palco italiano como espaço cênico, possibilitando a utilização de novos espaços; o improviso se torna uma ferramenta de composição, se dá mais valor ao processo que ao produto, se introduzem os gestos cotidianos na movimentação cênica, as técnicas tornam-se difusas e mistas, a composição coreográfica permite-se o acaso. A dança, dessa forma, explora novos caráteres performativos de sua linguagem: no espaço, na composição, na movimentação, na técnica.

Se antes, no teatro dramático, o termo "dramaturgia" estava intimamente relacionado com a representação do texto teatral, considerando suas rubricas e didascálias, com a quebra da hegemonia da representação o teatro considerado "pós-dramático" (LEHMANN, 2007) assume novas formas de apresentar esse texto, instalando-o mais do que representando, muitas vezes sem sequer utilizar texto. $O$ texto teatral se modifica, experimentando novas estruturas e gêneros, permitindo que a encenação não se limite a ele para acontecer.

$\mathrm{Na}$ dança, se antes podíamos compreender a dramaturgia como um conjunto de elementos cênicos (música, cenário, representação, técnica) que convergiam em favor de uma narrativa, com a dança contemporânea esse termo se torna difuso perante a pluralidade de discursos paralelos existentes em uma mesma cena.

Esse novo panorama aproximou o termo "dramaturgia" da produção de sentido que se torna variável tanto de criador para criador quanto da relação estabelecida com o espectador. A hierarquia antes fundada sobre o dramaturgo ou diretor é dissolvida agora entre os atores e bailarinos que participam ativamente da criação, incluindo os processos de montagem e produção. Os espetáculos autorais ganham mais voz e espaço, possibilitando o aparecimento da função de intérprete-criador. Com esse novo entendimento, a dramaturgia dialoga agora com a multiplicidade de vozes internas da criação e pode ser apreendida pelo espectador mais como um modo de enunciação do que como um texto, mais como uma duração polifônica do que como um tempo linear.

Com o intuito de estender o termo dramaturgia a todas as artes da cena, ressaltar a oposição dramaturgia contemporânea versus dramaturgia clássica, literária e de legitimar as muitas vozes autorais do produto cênico, começam a aparecer novos termos como dramaturgia do ator, dramaturgia do espaço, dramaturgia do quadro, dramaturgia do corpo, 
dramaturgia do bailarino, dramaturgia da dança, dramaturgia de tensões, etc. (TOURINHO, 2009, p. 89)

Cada discurso, cada dramaturgia, se apresenta como um significante aberto para o público, cabendo somente a ele articular e produzir o sentido que Ihe convier. Na mudança estética de paradigmas da modernidade, os gêneros representacionais passam do realismo à abstração, passando pela "emancipação dos significantes para chegar numa suspensão do significado" (POSCHMANN, 1997, p. 23, tradução nossa).

O espectador se torna assim um agente ativo na produção de sentido do espetáculo, formulando e articulando os possíveis significantes para construir seu próprio entendimento da(s) dramaturgia(s) apresentada(s): o público passa de voyeur para agente produtor de discurso. $O$ discurso se desvincula do eixo intraficcional e abre espaço para significação a partir de um eixo extraficcional. $\mathrm{O}$ real $\mathrm{e}$ o ficcional se tornam relativos à percepção do espectador e ao contexto no qual está inserido. Dessa forma, a dramaturgia se desfaz de uma compreensão textual e passa a uma percepção subjetiva e contextual.

\section{O performativo e o representativo na dramaturgia da cena híbrida contemporânea}

Nesse panorama, a categorização de linguagens se torna problemática. O que se observa na cena são efeitos de performatividade ou representatividade e técnicas mistas (teatro, dança, circo etc.) em prol de uma experiência estética. Féral (2008), em princípio, opõe o conceito de representatividade ao de performatividade, entendendo a primeira como uma estrutura narrativa que inscreve simbolicamente o discurso, enquanto a última, através de uma força dinâmica, expressa fluxos de desejo e tem como objetivo desconstruir a semiologia. No entanto, Gumbrecht (2010) relaciona performatividade à cultura de presença, que produz efeitos de presença, e representatividade à cultura do sentido, gerando efeitos de sentido. Embora toda sociedade tenha ambas, a cultura de sentido se relaciona mais diretamente ao significado, ao individualismo e ao pensamento, enquanto a cultura de presença se manifesta na relação direta com o corpo, a cosmologia e o espaço. 
Se para Féral (2008), ainda que na oposição dos conceitos, a cena acontece pelo jogo de forças resultante desses dois vetores (representatividade/ performatividade), também para Gumbrecht (2010) a experiência estética, ou seja, o momento de intensidade dado pela fruição do encontro entre o espectador e a obra em uma circunstância extraordinária, acontece quando há oscilação ou tensão entre os efeitos de sentido e os efeitos de presença. Ela acontece de modo espontâneo e imprevisível, e o espectador não consegue precisar sua origem, tampouco descrever seus significados. Como pensar então a construção de uma dramaturgia cênica a partir dos elementos de performatividade e representatividade?

Ora, duas categorias nomeadamente híbridas da contemporaneidade são o Teatro Físico e a Dança-Teatro. Essas duas linguagens, que emergem com força na última metade do século $\mathrm{XX}$, trabalham com a mescla de ferramentas metodológicas da dança e do teatro e promovem uma estética potente de alternância entre a representação e a apresentação. Exemplos históricos dessas vertentes são a Dança-Teatro de Pina Bausch e o Teatro Físico de Grotowski.

Se em Bausch podemos observar a inclusão do gesto cotidiano na dramaturgia do corpo, considerando as características psicológicas de seus bailarinos e valorizando suas diferenças em vez de tentar padronizar os corpos, por outro lado Grotowski investe na corporeidade de seus atores, buscando um teatro sem obstáculos físicos ou psicológicos para um encontro essencial entre ator e espectador. Todavia, há uma diferença estrutural entre essas duas linguagens, que Romano (2005) expressa bem na passagem a seguir:

O Teatro Físico e a Dança-Teatro, no entanto, traduzem respostas diferentes para "o quê" representar e "como" fazê-lo. Na operação de hibridização da Dança-Teatro, busca-se a autonomia da dança. A "flecha" da síntese pretendida parte da dança, apontando para o teatro, como se a primeira quisesse fagocitar o segundo. $O$ processo de Teatro Físico é semelhante ao anterior, mas segue uma "direção de contágio" diferente, partindo do teatro para a dança. Na genealogia desse modo de fazer teatral, podem ser incluídas as influências recíprocas entre o teatro e dança do século XX, mas operando em nome de uma autonomia do teatro. (p. 42-43) 
Partindo dessa perspectiva, levantamos as questões: será que a Dança-Teatro ou o Teatro Físico representam a performatividade ou performam a representatividade? Será que há diferença nesses binômios e, se sim, onde estaria essa diferença? Em que medida se trata apenas de uma inversão da "flecha da síntese" (partir da dança para o teatro ou do teatro para a dança) ou de uma mudança estrutural na dramaturgia?

Para Féral (2008), para além do termo "teatro pós-dramático", fundado por Lehmann (2007), a contemporaneidade se inscreve em um "teatro performativo", beneficiado pelas conquistas da arte da performance através das mudanças de paradigmas de se pensar a arte e originando o próprio termo "performatividade". A ênfase da cena recai sobre a ação e não mais sobre a representação. A situação faz prevalecer o real, o instantâneo e não repetível em vez de uma ilusão ficcional, mergulhando o espectador em uma experiência sensorial e perceptiva, condizente com a própria era tecnológica.

Por outro foco, e paralelamente, Deleuze (2007), quando se debruça sobre a obra do pintor Francis Bacon, se questiona como o pintor consegue pintar a Figura sem ser figurativo tampouco abstrato. Para o autor, "há duas maneiras de ultrapassar a figuração (quer dizer, tanto o ilustrativo, quanto o narrativo): em direção à forma abstrata, ou em direção à Figura. Cézanne deu a essa via da Figura um nome simples: a sensação" (p. 42). Desse modo, Bacon é um pintor de forças. Seus quadros, ainda que exponham figuras, não são representativos, mas promovem intensidades.

Analogamente, as artes cênicas não poderiam se desfazer da Figura-Corpo, pois essa é sua matéria fundamental, e em grande maioria é por ela, dela e nela que se faz a linguagem. É possível então construir uma dramaturgia que não recaia nem sobre a figuração nem sobre a abstração? Seria o teatro performativo esse teatro de forças que articula performatividade e representatividade em intensidades que ultrapassam o sentido sem negá-lo? Ou, ainda, em que medida é possível relacionar a performatividade de Féral, a presença de Gumbrecht, as intensidades de Deleuze com a presença cênica do ator? Será que poderíamos considerar a presença cênica como esse elemento intangível transformador e promotor da tensão entre efeitos de sentido e efeitos de presença, articuladores da experiência estética? 
A seguir, delinearemos breves análises a partir da observação do espetáculo Piracema, de Lia Rodrigues, contextualizando-o com seu local de produção e sua produção artística, no intuito de esclarecer ou problematizar as questões apontadas anteriormente.

\section{Figuras borradas na dramaturgia coral de Lia Rodrigues em Piracema}

A Lia Rodrigues Companhia de Danças é uma companhia brasileira dirigida por Lia Rodrigues que, embora seja denominada "companhia de dança", questiona categorizações. Sua cena apresenta elementos híbridos de várias linguagens (dança, teatro, artes visuais), além de uma tensão entre real/ficcional, performatividade/representatividade. Tampouco o trabalho de Lia Rodrigues pode ser encaixado nos rótulos de Dança-Teatro ou Teatro Físico, mas é um exemplo nítido das barreiras movediças da cena contemporânea.

Suas obras espelham expressividade política e são marcadas pelo impacto estético e artístico de seu material. Aquilo de que somos feitos (2000) foi um marco na dança contemporânea carioca ao apresentar bailarinos nus e seminus questionando o valor do corpo e a supremacia do mercado e do consumo, apresentando uma estrutura coreográfica que dinamitava as delimitações do espaço cênico, valorizava pausas, silêncios e imobilidade, e utilizava slogans de marcas conhecidas como texto falado.

A companhia foi fundada em 1990 e desde 2009 passou a ter sede no Centro de Artes da Maré, um espaço cultural de formação, criação e difusão das artes, também coordenado por Rodrigues, inserido na comunidade da Maré, um complexo de favelas que se localiza na periferia da cidade do Rio de Janeiro. Os primeiros espetáculos ali criados foram Pororoca (2009), Piracema (2011) e Pindorama (2013). Essas criações dialogam diretamente com a realidade social na qual a companhia está inserida e seus contrastes. Seu contexto condiz com a entrada, integração e permanência da sede da companhia em um centro de artes fora do eixo cultural comercial da cidade, em uma localização pouco visada pelos artistas e produtores cariocas. Ainda que de modo não panfletário, é inegável que esse deslocamento transparece em seus espetáculos. 
As obras Pororoca, Piracema e Pindorama guardam muitas semelhanças, como um tríptico, e Piracema é a segunda da trilogia. À primeira vista, o desenho espacial e a lógica coreográfica são muito similares; no entanto, cada obra possui uma dramaturgia que provoca uma sensação e um entendimento diferente e que se relaciona diretamente com o tempo de permanência da companhia no Centro de Artes da Maré.

"Piracema", na língua Tupi, significa a viagem dos peixes e cardumes em direção à nascente, contra a correnteza. "Pororoca", por sua vez, significa estrondar, ou o fenômeno natural do encontro do rio com o mar. As duas criações afirmam o desejo dos laços sociais e relações com o ambiente que escolheram como sede de trabalho e o compromisso com eles. Em Pororoca, a primeira criação, essas formas de convívio são representadas pelo choque, pelo embate, pelo ataque, mas também com desejo de permanência. Em Piracema, novos modos de coabitação são manifestados.

Construído a partir de onze solos criados pelos bailarinos da companhia, Piracema carrega na sua dramaturgia a tensão constante entre o individual e o coletivo, em fricções das relações subjetivas e contextuais. Em ambas as peças, os bailarinos permanecem juntos no espaço, desenhando um percurso objetivo, como um coro destinado a cumprir uma trajetória. $A$ movimentação segue um tempo de fluxo constante e contínuo que, em uma metáfora, se assemelha ao movimento das águas.

Se em Pororoca essa movimentação acontece com a manipulação de cadeiras de plástico, em que os bailarinos colocam e retiram as cadeiras ao longo de um percurso coreográfico delimitado, provocando um barulho estrondoso e confusão visual, em Piracema, sem nenhum elemento cênico externo ao corpo, os bailarinos afirmam individualidades executando partituras coreográficas distintas, mas permanecendo unidos no desenho coral do percurso no espaço. As partituras individuais não dialogam entre si, mas interferem-se espacialmente e repetem-se ao longo da duração do percurso.

As individualidades emergem dentro do coletivo e é possível observar expressões de rostos, vozes, canto, emoções, sensações em um coro polimorfo e efêmero. Nessas partituras individuais reconhecemos figuras e podemos associar personagens a algumas passagens no espaço, mas a transitoriedade do movimento coloca o espectador sempre em questão: 
estariam eles representando ou apresentando-se? Estariam representando a si próprios em partituras autorais?

Como analisar a performatividade e a representatividade desse espetáculo? Se ativermos atenção a apenas um dos bailarinos ao longo de todo o percurso, poderíamos dizer que, em virtude das movimentações particulares e expressivas em que reconhecemos figuras cotidianas, o espetáculo tem caráter representativo. Todavia, se observamos o espetáculo como um todo, a coralidade - no sentido exposto por Triau (2003) - da composição coreográfica faz essa tensão entre individual e coletivo oscilar nossa visão e percepção entre o particular e o geral, provocando uma sensação de figuras que se borram, que nunca se completam e se misturam constantemente em um fluxo contínuo e compartilhado de desenho no espaço, suscitando o caráter performativo.

A polivalência dos significantes (corpos, figuras, espaço) desperta uma tensão no espectador entre o que é real e o que é ficcional, em uma alternância entre presença e significação. Se pela força do hábito impressa na nossa cultura do sentido permanecemos em busca de uma interpretação, um significado ou uma narrativa, logo somos apreendidos pelo fluxo dinâmico de sensações, em um tempo imediato do acontecimento instantâneo, de duração constante, sem início, meio ou fim. Os efeitos de sentido se confundem com os efeitos de presença em um momento de instabilidade entre presente e história, contexto e subjetividade.

A coralidade se manifesta em uma polifonia de vozes e plasticidades da forma, desviando o centro da representação da personagem para dar um novo foco à questão: como estar juntos permanecendo singulares? Piracema assim se apresenta e condiz com seu contexto de entrada na comunidade da Maré. A tensão entre o individual e o coletivo revela o desejo de pertencimento sem esconder a fragilidade que a sociedade e a cultura lhes impõem. É nesse impulso motor que as figuras se borram e se alternam em imagens e sensações, em contexto, subtexto, entendimento e presença, sustentando uma tensão constante entre o estar e o pertencer, entre o micro e o macro, do sujeito na arte, da arte na vida, do homem no mundo.

\section{Considerações finais}


A presença cênica está no âmbito do intangível tornando-se incomensurável, embora percebida e apreendida. A representatividade e a performatividade, por sua vez, apresentam elementos bem distinguíveis, mas quando colocadas em atrito na forma do espetáculo acabam contaminando barreiras. Os efeitos de sentido são percebidos de acordo com o aparato contextual perceptivo e cognitivo do receptor (espectador), assim como a dramaturgia será fruto de uma sua elaboração significante. Em vez de querer relativizar todos os conceitos sem chegar a uma conclusão, o que propomos é que, através da análise e observação dos contextos da obra e dos sujeitos presentes na sua produção, se entenda a especificidade e a particularidade de cada encontro a partir da experiência estética, revelando que categorizações de linguagens e procedimentos, na contemporaneidade, parecem, dessa forma, ineficientes.

Piracema não representa seu contexto, não panfleta um discurso, não apresenta uma narrativa. Piracema está no presente, é fluxo constante, apresenta Figuras, revela a fragilidade do coro. Piracema é e não é: acontece. Acontece de modo específico e particular para cada um e propõe assim uma experiência única de acordo com o aparato cognitivo do espectador.

Onde está Piracema? Na Maré, no teatro, na Lia, nos bailarinos, nos corpos, no Rio de Janeiro, no imaginário, nas imagens, nos livros, nos discursos... aqui e em lugar nenhum. Como faz Piracema? Com técnicas e invenções, discursos e fantasias, sopros e sopas da nossa multiplicidade de procedimentos contemporâneos. A obra não se classifica, tampouco se desclassifica. Nessa miscelânea de processos, o espectador é o fundador da verdade. Se para ele a experiência teve eco, objetivo alcançado, se não, sua memória brevemente será trocada pela primeira sensação que aparecer.

Arte continua se fazendo por necessidade, e não por receitas. As categorias não bastam para explicar experiências. Mas é sempre à guisa de tensões que se faz o mundo. A corda frouxa desaba. A tensão sustenta.

\section{Referências bibliográficas}

DELEUZE, G. Francis Bacon: lógica da sensação. Rio de Janeiro: Jorge Zahar, 2007. FÉRAL, J. Por uma poética da performatividade: o teatro performativo. Sala Preta, v.

8, p. 197-210, 2008. DOI: http://dx.doi.org/10.11606/issn.2238-3867.v8i0p197-210 FERNANDES, S. Teatralidades contemporâneas. In: BRILHANTE, M. J.; WERNECK, 
M. H. (Orgs.). Texto e imagem: estudos de teatro. Rio de Janeiro: 7 letras, 2009.

p. 9-27.

FREIRE, C. Arte Conceitual. Rio de Janeiro: Jorge Zahar, 2006.

GUMBRECHT, H. U. Produção de presença: o que o sentido não consegue transmitir. Rio de Janeiro: Contraponto; PUC-Rio, 2010.

HARVEY, D. Condição Pós-Moderna. São Paulo: Loyola, 2006.

LEHMANN, H-T. Teatro pós-dramático. São Paulo: Cosac Naify, 2007.

POSCHMANN, G. Der nicht mehr dramatische Theatertext: Aktuelle Bühnenstücke und ihre dramaturgische Analyse. Tübingen: Niemeyer, 1997.

ROMANO, L. O teatro do corpo manifesto: teatro físico. São Paulo: Perspectiva; Fapesp, 2005.

TOURINHO, L. L. Dramaturgias do corpo: protocolos de criação das Artes da Cena. 2009. Tese (Doutorado em Artes) - Universidade Estadual de Campinas, Campinas, 2009.

TRIAU, C. Choralités diffractées: la communauté en creux. Alternatives théâtrales, n. 76-77, p. 5-11, jan. 2003.

Recebido em 07/09/2016

Aprovado em 30/10/2016

Publicado em 21/12/2016 